cusps of equal size, whereas other anatomic patterns, as in our case, are more difficult to detect. This explains why many cases of quadricuspid aortic valves are still occasional surgical or necropsy findings. ${ }^{4,5}$

In our patient, a quadricuspid aortic valve, which may be identified as type $\mathrm{C}$ according to the Hurwitz-Roberts classification, ${ }^{1}$ was associated with a hypoplastic aortic annulus. This finding, not previously recognized even in a comprehensive review, ${ }^{4}$ required a more technically demanding surgical procedure. The present case illustrates such an unusual combination, indicating that occasionally a quadricuspid aortic valve may be part of a more complex pathologic condition of the left ventricular outflow tract.

\section{References}

1. Hurwitz LE, Roberts WC. Quadricuspid semilunar valves. Am J Cardiol. 1973; 31: 623-6.

2. Mecozzi G, Pratali S, Milano A, Nardi C, Bortolotti U. Severe quadricuspid aortic valve stenosis after mediastinal irradiation. J Thorac Cardiovasc Surg. 2003;126:1198-9.

3. Bortolotti U, Scioti G, Milano A, Nardi C, Tartarini G. Enlargement of the aortic annulus with glutaraldehyde-fixed bovine pericardium during aortic valve replacement. J Heart Valve Dis. 1998;7:299-304.

4. Turatel $\mathrm{O}$. The quadricuspid aortic valve: a comprehensive review. J Heart Valve Dis. 2004;13:534-7.

5. Jannssens U, Klues HG, Hanrath P. Congenital quadricuspid aortic valve anomaly associated with hypertrophic non-obstructive cardiomyopathy: a case report and review of the literature. Heart. 1997;78:83-7.

\title{
Repair for a duplicate mitral valve with torn chordae
}

Kohei Ando, MD, Yukihiro Tomita, MD, Munetaka Masuda, MD, Atsuhiro Nakashima, MD, and Ryuji Tominaga, MD, Fukuoka, Japan

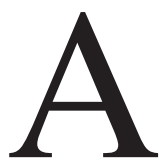

duplicate mitral valve is especially uncommon in patients with double-orifice mitral valve (DOMV). ${ }^{1} \mathrm{We}$ herein report a case demonstrating an isolated duplicate mitral valve with a torn chordae in which mitral valvuloplasty was undertaken successfully.

\section{Clinical Summary}

A 46-year-old male patient with severe mitral regurgitation (MR) was admitted to our department. He had had dyspnea for 5 months, which had gradually worsened over time. A regurgitant systolic murmur, grade $4 / 6$, was audible at the apex. Left ventricular angiography showed severe grade 4/4 MR. An echocardiogram indicated a diagnosis of torn chordae at the posteromedial scallop of the posterior mitral leaflet.

A preoperative Doppler echocardiogram showed the area of the two mitral orifices to measure $5.5 \mathrm{~cm}^{2}$ in size on the posteromedial side and $2.4 \mathrm{~cm}^{2}$ in size on the anterolateral side (Figure 1). Severe MR caused by torn chordae was found only from the lateral mitral valve. The tissue separating the two orifices looked stiff, in contrast to the fibrous string connecting the two leaflets. The chordae of the two mitral valves were folded into each of the papillary

From the Department of Cardiovascular Surgery, Faculty of Medicine, Kyushu University, Fukuoka, Japan.

Received for publication Jan 18, 2007; revisions received March 21, 2007; accepted for publication April 20, 2007.

Address for reprints: Yukihiro Tomita, MD, Associate Professor, Department of Cardiovascular Surgery, Faculty of Medicine, Kyushu University, 3-1-1 Maidashi, Higashi-ku, Fukuoka 812-8582, Japan (E-mail: tomita@ heart.med.kyushi-u.ac.jp).

J Thorac Cardiovasc Surg 2007;134:1062-3

$0022-5223 / \$ 32.00$

Copyright @ 2007 by The American Association for Thoracic Surgery doi:10.1016/j.jtcvs.2007.04.036 muscles, on the posteromedial and anterolateral sides. As a result, the two mitral valves seemed to be independent of each other, including the subvalvular apparatus. Other findings were as follows: the left ventricular ejection fraction was $59 \%$ and the tricuspid regurgitation was grade 2 .

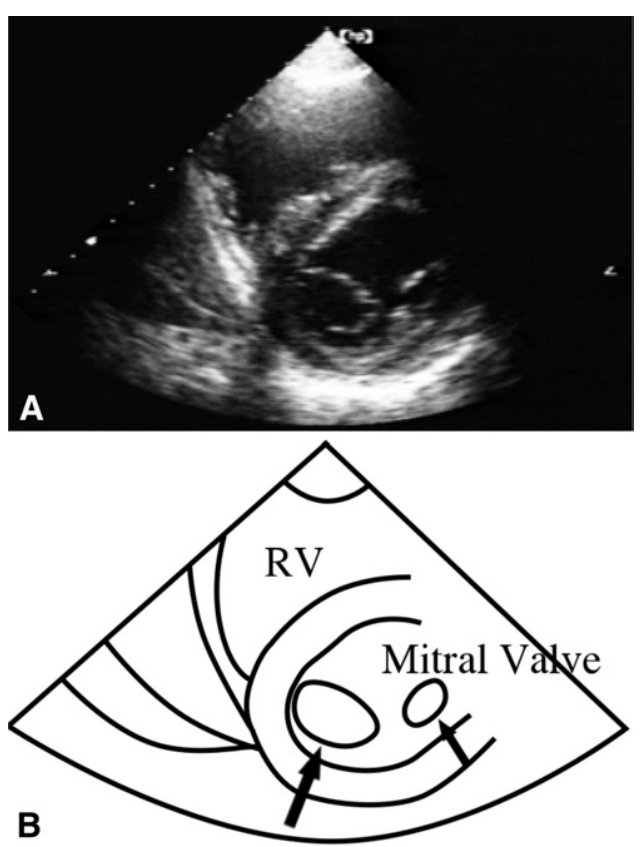

Figure 1. Two-dimensional echocardiogram showing duplicate mitral valve. Short-axis view of left ventricle. Two mitral valve orifices are shown. The posteromedial orifice (large arrow) is larger than the anterolateral one (small arrow). Right ventricular overload is also observed (flattening of ventricular septal wall). 

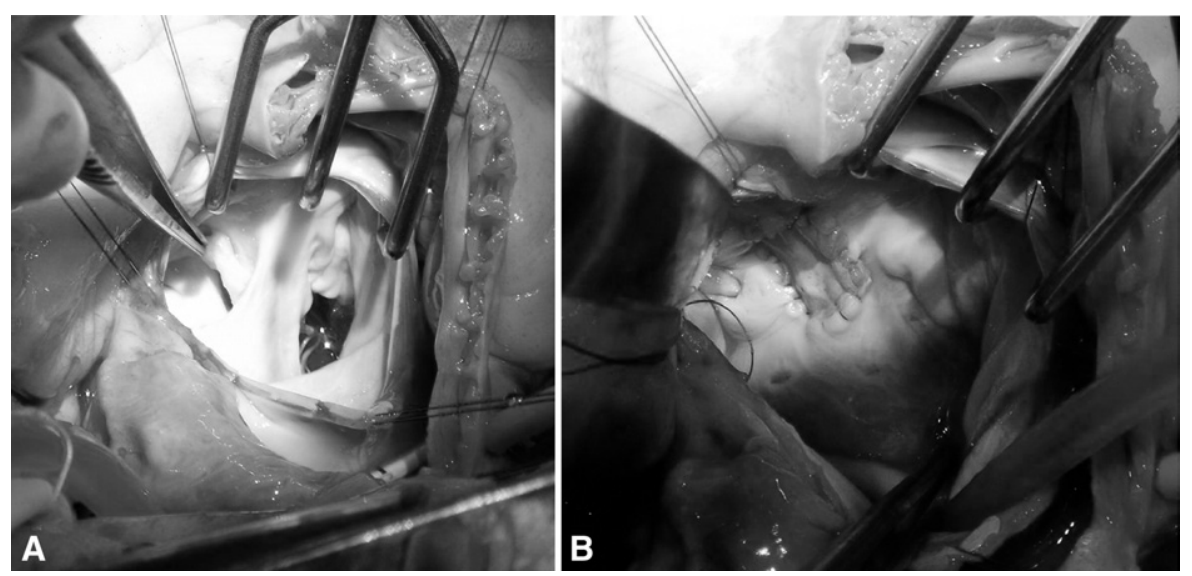

Figure 2. Intraoperative finding of duplicate mitral valve. A, Duplicate mitral valve is shown. The subvalvular apparatus is also duplicated. Central bridging tissue was fibrous and stiff. Forceps picked up torn chordae in the anterolateral valve. B, Lateral smaller mitral valve annulus was closed. After direct closure of the two leaflets, the smaller valve was covered by an autologous pericardial patch.

Through a median sternotomy, cardiopulmonary bypass with mild hypothermia $\left(34^{\circ} \mathrm{C}\right)$ was instituted. After induction of cardiac arrest, the left atrial cavity was exposed through the superior transseptal approach. On inspection, each mitral valve was found to consist of a stiff annulus (Figure 2). The intact mitral valve on the posteromedial side seemed sufficiently large and a 29-mm sizer could pass through it. We therefore judged that the mitral valve could be repaired by direct closure of the lateral mitral valve alone. After the direct closure of the anterolateral orifice, the closed orifice was covered with an autologous pericardial patch to reinforce the closure. Sometimes, after such a repair, another untouched valve is accidentally damaged or disrupted and the coaptation changes of such a valve may thus cause iatrogenic regurgitation. ${ }^{2}$ Therefore, before closing the left atrial cavity, we filled the left ventricular cavity with cold saline again to ensure that regurgitation through the mitral valve was absent. Intraoperative transesophageal echocardiography showed no MR, and it therefore provided us with evidence of a successful repair.

Thereafter, the postoperative recovery was uneventful. At discharge, a postoperative transthoracic echocardiogram showed no MR. Left ventricular inflow peak velocity was $109 \mathrm{~cm} / \mathrm{s}$. Mitral valve area was $2.59 \mathrm{~cm}^{2}$ calculated from pressure half-time. The cardiac index was $2.8 \mathrm{~L} \cdot \min ^{-1} \cdot \mathrm{m}^{-2}$. Furthermore, similar echocardiographic results were obtained (trivial MR, mitral valve area $2.47 \mathrm{~cm}^{2}$, inflow peak velocity $109 \mathrm{~cm} / \mathrm{s}$ ) 1 year after the operation. The patient was carefully followed up and has been doing well (New York Heart Association class I) during the follow-up period. In addition, he was able to successfully return to his job.

\section{Discussion}

Duplicate mitral valve is a very uncommon congenital heart anomaly among all the reported cases of DOMV. DOMV is classified as hole type $(85 \%)$, bridge type $(15 \%)$, and duplicate mitral valve. ${ }^{3}$ To the best of our knowledge, according to a PubMed search, no report concerning a duplicate mitral valve has yet been published.
In duplicate mitral valve cases, two independent mitral valve apparatuses (leaflets and annulus) and subvalvular apparatuses (chordae and papillary muscles) function well by themselves, and they usually do not coexist with any other heart anomaly. As a result, it is extremely uncommon to find a patient with duplicate mitral valve unless the patient has some other problem. Some studies have reported that merely cutting the bridging tissue is unsuccessful. ${ }^{1,2}$ Mitral valvuloplasty, which is the reconstruction of torn chordae without touching other native apparatuses including bridging tissue, has been performed successfully. ${ }^{1}$ In other cases, however, merely cutting the bridging tissue has also yielded satisfactory results. ${ }^{4}$ Another study obtained successful results by performing mitral valve replacement for DOMV. ${ }^{5}$ In our case, however, two complete mitral valve annuli existed. As a result, it remains doubtful whether normal mitral valve replacement could have been performed. Fortunately, the good functioning mitral valve had a sufficient orifice area in this case. We believe that a direct closure of the deficient mitral valve was the best option to maintain postoperative left ventricular function, shorten the operation time, and avoid postoperative anticoagulation.

We thank Brian Quinn, medical editor of Kyushu University Medical School.

\section{References}

1. Bano-Rodrigo A, Van Praagh S, Trowitzsch E, Van Praagh R. Doubleorifice mitral valve: a study of 27 postmortem cases with developmenta, diagnostic and surgical considerations. Am J Cardiol. 1988;61:152-60.

2. Tomita Y, Yasui H, Tominaga R. Mitral valve repair for isolated double-orifice mitral valve with torn chordae. Ann Thorac Surg. 1997; 64:1831-4.

3. Trowitzsch E, Bano-Rodrigo A, Burger BM, Colan SD, Sanders SP. Two-dimensional echocardiographic findings in double orifice mitral valve. J Am Coll Cardiol. 1985;6:383-7.

4. Reed GE, Cortes LE, Clauss RH, Repert EH. The surgical repair of duplication of the mitral orifice. Ann Thorac Surg 1970;9:81-5.

5. Kron J, Standerfer RJ, Starr A. Severe mitral regurgitation in a woman with a double orifice mitral valve. Br Heart J. 1986;55:109-11. 